\title{
Desain Antena Hexagonal Patch Array untuk Peningkatan Gain dan Bandwidth pada Frekuensi 2,4 GHz
}

\author{
Herma Nugroho R A K \\ Politeknik Kota Malang \\ Jl. Tlogowaru No 3Kedungkandang Malang, (0341) 754088 \\ e-mail: hnugroho81@gmail.com
}

\begin{abstract}
Abstrak - Pada penelitian ini telah didesain antena hexagonal single patch dan hexagonal patch array yang dapat digunakan sebagai perangkat antena untuk menangkap gelombang radio (RF) pada frekuensi 2,4 GHz pada Wireless Local Area Network (WLAN). Desain antena dilakukan menggunakan software CST 2015 (Student Version) Microwave studio. Parameter pengujian antena hexagonal patch array meliputi return loss, gain, dan bandwidth. Metode yang digunakan adalah pemodelan transmission line dan corporate feed line untuk pengaturan perubahan jarak antar patch antena. Perubahan variabel juga diteliti pengaruhnya terhadap parameter antena khususnya gain antena. Nilai parameter antena hasil simulasi antena hexagonal patch array menunjukkan nilai return loss adalah -20, $081 \mathrm{~dB}$, gain sebesar 3,51 dB, bandwidth adalah 0,05 GHz. Sedangkan nilai parameter antena hasil simulasi antena hexagonal patch array menunjukkan nilai return loss adalah $-33,94 \mathrm{~dB}$, gain sebesar 5,55 dB, bandwidth adalah 0,08 $\mathrm{GHz}$.
\end{abstract}

Kata kunci: patch, array, return loss, gain, bandwidth

\section{Pendahuluan}

Salah satu komponen penting dalam teknologi telekomunikasi khususnya teknologi tanpa kabel (wireless) adalah antena. Antena merupakan suatu sarana yang digunakan untuk memancarkan dan menerima gelombang elektromagnetik [1]. Desain antena untuk mendukung teknologi wireless terus dikembangkan karena perkembangan teknologi ini semakin pesat untuk bermacam-macam aplikasi misalnya untuk aplikasi Wireless Local Area Network (WLAN).

Saat ini aplikasi WLAN dibedakan menjadi 2 macam yaitu indoor dan outdoor. Di area indoor WLAN banyak digunakan di area perkntoran (ruang rapat, ruang kerja), kampus (perpustakaan, ruang seminar, ruang kelas), hot spot (kafe, executive longue, ruang tunggu, kantin). Sedangkan outdoor WLAN banyak dipakai untuk menghubungkan antar gendung, jaringan di taman, perkotaan, tempat parkir, jalan raya dan lain sebagainya. Berdasarkan jenis aplikasi WLAN tersebut maka diperlukan antena yang mampu memberikan kinerja yang baik terutama dalam kecepatan mentransmisikan data. Selain itu, antena juga harus memiliki desain yang simpel dan ukuran yang relatif kecil.

Kinerja antena yang baik akan mempengaruhi kualitas sinyal yang diterima, sehingga berdampak pada kecepatan data teknologi WLAN. Oleh karena itu untuk mendukung teknologi WLAN dengan kecepatan tinggi diperlukan antena yang memiliki karakteristik bandwidth dan gain yang besar [2]. Salah satu pilihan antena yang sesuai dengan kriteria tersebut adalah antena mikrostrip. Beberapa keuntungan antena mikrostrip adalah dapat diterapkan untuk komunikasi wireless misalnya pada telemetri, radar, sistem GPS dan pemandu senjata secara otomatis . Sedangkan kelemahannya adalah memiliki band frekuensi yang terbatas, tidak bisa digunakan pada daya operasi yang besar dan memerlukan ketelitian yang tinggi dalam desain dan implementasi.

TELKA, Vol.2, No.1, Mei 2016, pp. 44 52 
Berdasarkan hasil penelitian antena mikrostrip sebelumnya, tentang desain antena hexagonal fractal array dengan metode feeding koaksial menunjukkan bahwa pada frekuensi 2,4 GHz iterasi pertama masih relatif kecil yaitu gain sebesar 3,28 dB [3], sehingga diperlukan suatu metode desain untuk peningkatan gain antena.

Secara garis besar metode desain yang digunakan pada antena mikrostrip array adalah metode corporate feed line dan series feed line. Berdasarkan penelitian sebelumnya bahwa metode series feed line memiliki beberapa kelemahan antara lain nilai gain dan return loss yang rendah. Sedangkan pada corporate feed line memiliki beberapa kelebihan antera lain mudah dalam implementasi, adanya kontrol daya pada saluran tiap elemen, gain dan return loss yang besar [4]. Fokus pada penelitian ini adalah desain antena dengan patch hexagonal array untuk peningkatan gain dan bandwidth yang diaplikasikan pada WLAN.

\section{Metodologi Penelitian}

Penggambaran tentang metode corporate feed line dapat dijelaskan pada feed antena array linear dengan 2 patch antena sesuai Gambar 1

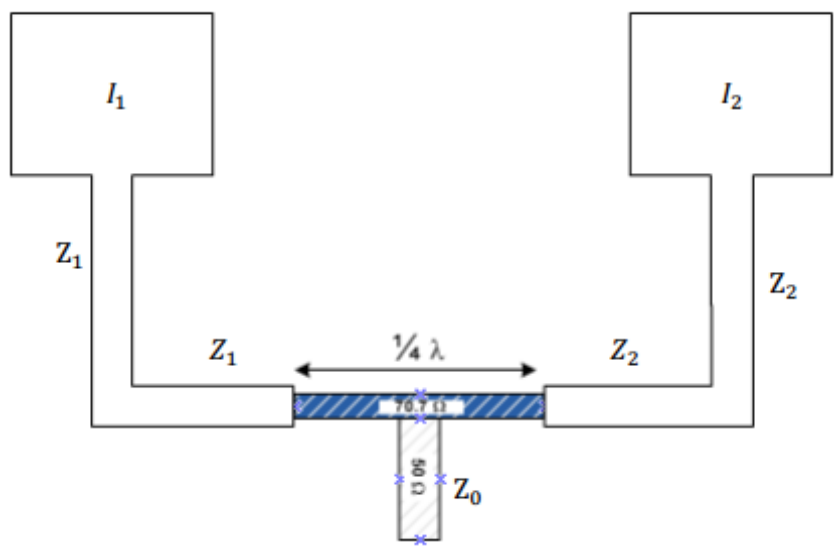

Gambar 1. Dua patch linear array dengan corporate feed [5]

Metode corporate feed line digunakan secara umum dan banyak diaplikasikan dalam berbagai bidang. Metode ini memiliki kontrol saluran di setiap patch dan sesuai pada penggunaan saluran yang meruncing kedua ujungnya atau pada transformer $1 / 4$ panjang gelombang $(\lambda)$ antena. Pada penelitian ini elemen patch dihubungkan dengan saluran pencatu dengan metode impedansi transformer $1 / 4 \lambda$ atau sering disebut teknik pembagi daya Wilkinson.

Setiap elemen yang sama dari patch antena memiliki resitansi input $R_{\text {in }}$. Elemen resistansi ini akan matched dengan impedansi saluran transmisi $Z_{1}, Z_{2}$ dan arus pada masing-masing patch $\left(\mathrm{I}_{1}\right.$ dan $\mathrm{I}_{2}$ ) yang digunakan untuk pembagian daya. Hal ini dapat dilakukan dengan teknik pembagian daya Wilkinson. Karakteristik impedansi $\sqrt{2} \mathrm{Z}_{0}$ dan isolasi lumped resistor $2 \mathrm{Z}_{0}$ dengan kondisi semua port bernilai sama $\mathrm{Z}_{1}=\mathrm{Z}_{2}=\mathrm{Z}_{0} \quad[6]$. 


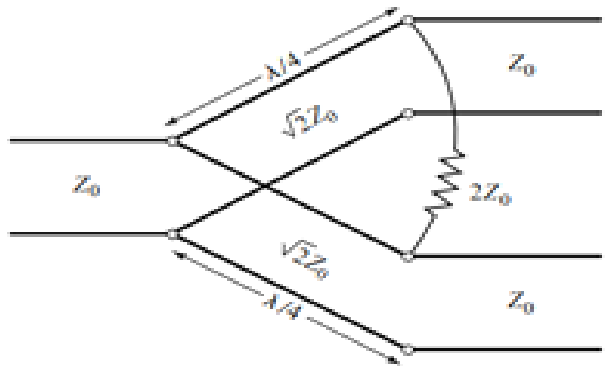

Gambar 2. Rangkaian ekivalen line transmisi Wilkinson [6]

\section{Hasil dan Analisis}

\subsection{Desain Antena Hexagonal Single Patch}

Desain awal antena mikrostrip yang dirancang adalah antena mikrostrip hexagonal single patch pada frekuensi 2,4 dengan metode pencatuan feed line. Substrat yang digunakan adalah FR4 Epoxy dengan konstanta dielektrik $\left(\varepsilon_{\mathrm{r}}\right)$ sebesar 4,3 dengan ketebalan substrat yaitu 1,5 $\mathrm{mm}$. Bahan patch adalah dari tembaga dengan ketebalan $0,5 \mathrm{~mm}$. Perancangan antena tersebut menggunakan software Computer Simulation Technology (CST) 2015 Microwave Studio (Student Version). Antena yang dirancang memiliki dimensi 30,5 x 38,5 mm.

Sebelum menentukan dimensi patch antena maka terlebih dahulu ditentukan panjang gelombang diruang bebas $\left(\lambda_{0}\right)$ dengan perambatan ruang bebas (c) sebesar $3 \times 10^{8} \mathrm{~m} / \mathrm{s}$ pada frekuensi kerja 2,4 GHz. Sesuai persamaan (1) [1] berikut diperoleh nilai $\lambda_{0}$ sebesar $125 \mathrm{~mm}$.

$$
\lambda_{0}=\frac{e}{f}
$$

Selanjutnya dilakukan penghitungan dimensi elemen peradiasi antena yang terdiri dari panjang sisi hexagonal antena (s), lebar (W) dan panjang (L) [1][7]. Panjang sisi hexagonal antena dan lebar antena dapat dihitung menggunakan persamaan (2) dan (3) sebesar 19,4 mm dan $38,5 \mathrm{~mm}$

$$
\begin{gathered}
\left.s=\frac{c}{3.103 a f_{\mathrm{r}} \sqrt{\varepsilon_{\mathrm{r}}}}\right) \\
W=\frac{c}{2 \mathrm{f}_{\mathrm{r}} \sqrt{\left(\mathrm{s}_{\mathrm{r}}+1\right) / 2}}
\end{gathered}
$$

Untuk menentukan panjang $(L)$ patch, maka terlebih dahulu ditentukan nilai konstanta dielektrik $\left(\varepsilon_{r e f f}\right)$ dan nilai panjang tambahan $\Delta L$ meggunakan persamaan (4) (5)

$$
\begin{aligned}
\varepsilon_{\text {reff }} & =\frac{\left(x_{r}+1\right)}{2}+\frac{\left(x_{r}-1\right)}{2}\left[1+12 \frac{\hbar}{W}\right]^{-1 / 2} \\
\frac{\Delta L}{h} & =0,412 \frac{\left.\left(x_{r a f f}+0, a\right)+\frac{W}{h}+0,264\right)}{\left(s_{r s f f}-1,258\right)\left(\frac{W}{h}+0,8\right)} \\
L_{\text {reff }} & =\frac{c}{2 f_{r} \sqrt{s_{\text {raff }}}} \\
L & =L_{\text {reff }}-2 \Delta L
\end{aligned}
$$

Berdasarkan hasil perhitungan dari persamaan (6) dan (7) diperoleh panjang patch sebesar 30,5 mm. Hasil perhitungan dari persamaan-persamaan tersebut kemudian diaplikasikan ke dalam simulasi antena menggunakan software CST Microwave studio. Geometri antena mikrostrip sesuai persamaan tersebut ditunjukkan pada Gambar 3. 


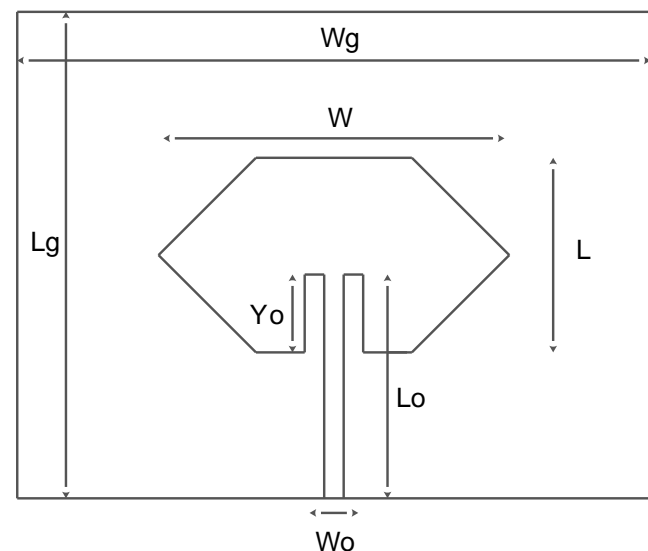

Gambar 3. Desain antena hexagonal single patch

Hasil dari desain ukuran geometri antena hexagonal single patch ditunjukkan pada Tabel 1.

Tabel 1. Ukuran dimensi antena hexagonal single patch

\begin{tabular}{|c|l|c|}
\hline $\begin{array}{c}\text { Dimensi } \\
\text { Antena }\end{array}$ & \multicolumn{1}{|c|}{ Keterangan } & $\begin{array}{c}\text { Ukuran } \\
(\mathbf{m m})\end{array}$ \\
\hline $\mathrm{L}$ & Panjang patch & 30,5 \\
\hline $\mathrm{W}$ & Lebar patch & 38,5 \\
\hline $\mathbf{W}_{\mathbf{0}}$ & Lebar saluran transmisi / feedline & 2,8 \\
\hline $\mathrm{S}$ & Panjang sisi hexagonal & 19,4 \\
\hline $\mathbf{W}_{\mathbf{g}}$ & Lebar minimum ground plane & 47,5 \\
\hline $\mathbf{L}_{\mathbf{g}}$ & Panjang minimum ground plane & 42 \\
\hline $\mathbf{Y}_{0}$ & Panjang saluran matching impedansi & 11,06 \\
\hline
\end{tabular}

\subsection{Desain Antena Hexagonal Patch Array}

Desain antena hexagonal patch array mengacu pada antena hexagonal single patch yaitu pada ukuran patch, lebar patch dan groundplane. Sedangkan hal yang membedakan antara keduanya adalah terletak pada panjang dan lebar saluran antara patch. Kedua parameter tersebut dapat ditentukan dari persamaan berikut

$$
l=\frac{1}{4} \pi g
$$

dengan,

$$
\lambda_{g}=\frac{x_{0}}{\sqrt{x_{0} f f}}
$$

Sedangkan lebar saluran pencatu $\left(W_{0}\right)$ adalah

$$
W_{6}=\frac{\pi n}{\pi}\left\{B-1-\ln (2 B-1)+\frac{z-1}{L+1}\left[\ln \left(B-1+0,39-\frac{0,01}{z}\right]\right.\right.
$$

dengan,

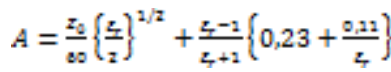

$$
\begin{aligned}
& B=\frac{\operatorname{man}^{2}}{\sin _{n} \sqrt{E_{1}}}
\end{aligned}
$$

Geometri antena mikrostrip sesuai persamaan tersebut ditunjukkan pada Gambar 4 . 


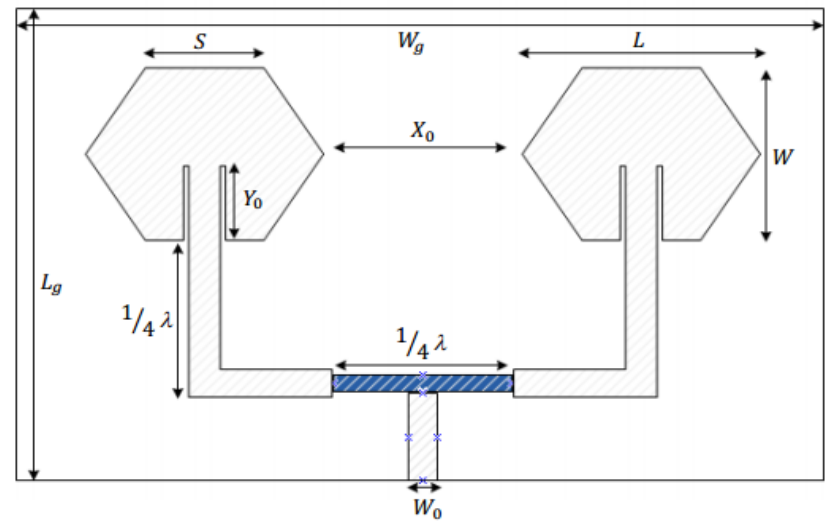

Gambar 4. Desain antena hexagonal patch array

Hasil dari desain ukuran geometri antena hexagonal patch array ditunjukkan pada Tabel 2

Tabel 2. Ukuran dimensi antena hexagonal patch array

\begin{tabular}{|c|l|c|}
\hline $\begin{array}{c}\text { Dimensi } \\
\text { Antena }\end{array}$ & \multicolumn{1}{|c|}{ Keterangan } & $\begin{array}{c}\text { Ukuran } \\
(\mathbf{m m})\end{array}$ \\
\hline $\mathrm{L}$ & Panjang patch & 30,5 \\
\hline $\mathrm{W}$ & Lebar patch & 38,5 \\
\hline $\mathbf{W}_{\mathbf{0}}$ & Lebar saluran transmisi / feedline & 2,8 \\
\hline $\mathrm{S}$ & Panjang sisi hexagonal & 19,4 \\
\hline $\mathbf{W}_{\mathbf{g}}$ & Lebar minimum ground plane & 47,5 \\
\hline $\mathbf{L}_{\mathbf{g}}$ & Panjang minimum ground plane & 42 \\
\hline $\mathbf{Y}_{0}$ & Panjang saluran matching impedansi & 11,06 \\
\hline $\mathbf{X}_{0}$ & Jarak antar sisi elemen & 24 \\
\hline
\end{tabular}

\subsection{Hasil Simulasi Antena Hexagonal Single Patch dan Patch Array}

Setelah dilakukan simulasi terhadap kedua desain antenna tersebut, didapatkan parameterparameter berikut:

\subsubsection{Return Loss}

Hasil simulasi return loss dari antena mikrostrip hexagonal single patch dan patch array ditunjukkan pada Gambar 5 dan Gambar 6

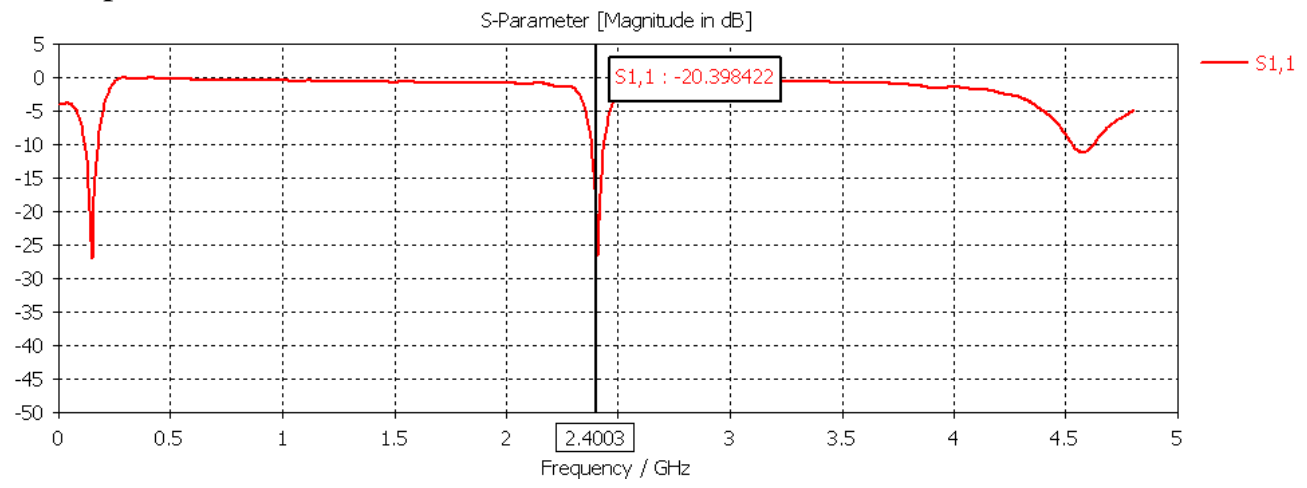

Gambar 5. Hasil simulasi return loss antena mikrostrip hexagonal single patch pada frekuensi $2,4 \mathrm{GHz}$ 


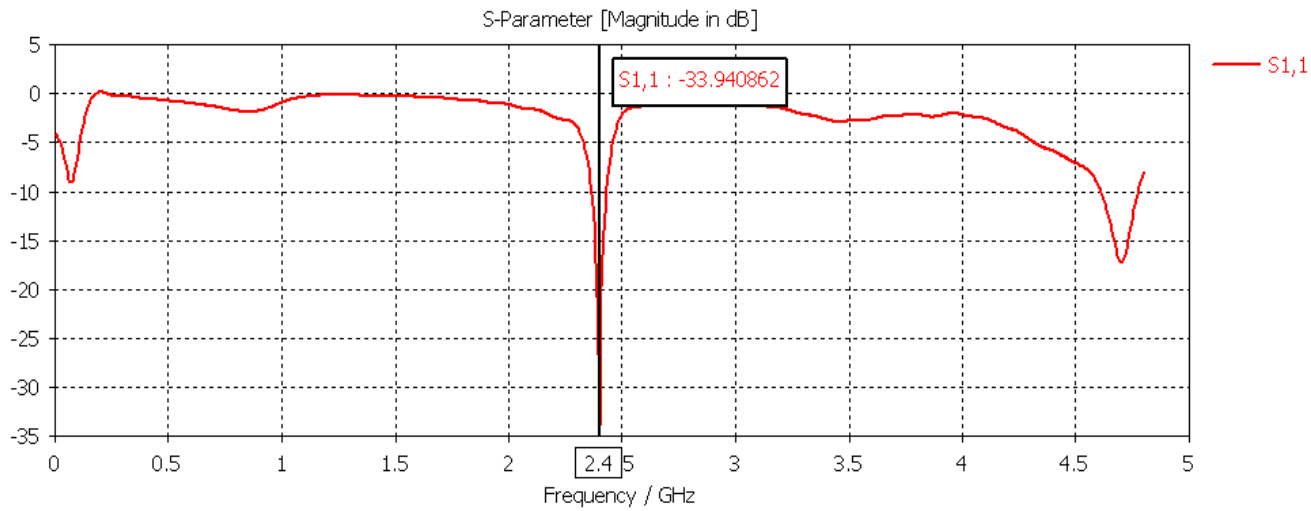

Gambar 6. Hasil simulasi return loss antena mikrostrip hexagonal patch array pada frekuensi $2,4 \mathrm{GHz}$

Berdasarkan Gambar 5 dan Gambar 6, hasil simulasi pengukuran return loss dari kedua antena, maka pada antena hexagonal single patch didapatkan nilai return loss - 20,081dB. Sedangkan pada antena hexagonal patch array diperoleh nilai return loss - 33, $94 \mathrm{~dB}$. Nilai return loss dari kedua antena berada jauh dibawah $-10 \mathrm{~dB}$ yang merupakan batas nilai return loss yang artinya daya yang dipantulkan sangat sedikit dan mendekati kondisi yang match antara transmitter dan beban/antena.

\subsubsection{Bandwidth (BW)}

Bandwidth antena merupakan range frekuensi antena dengan beberapa karakteristik, sesuai dengan standar yang telah ditentukan. Berdasarkan Gambar 7 dan 8 dapat diketahui nilai bandwidth suatu antena dengan cara menghitung selisih dari range frekuensi kerja atas $\left(\mathrm{f}_{\mathrm{u}}\right)$ dan frekuensi kerja bawah $\left(\mathrm{f}_{\mathrm{l}}\right)$ sesuai persamaan 13

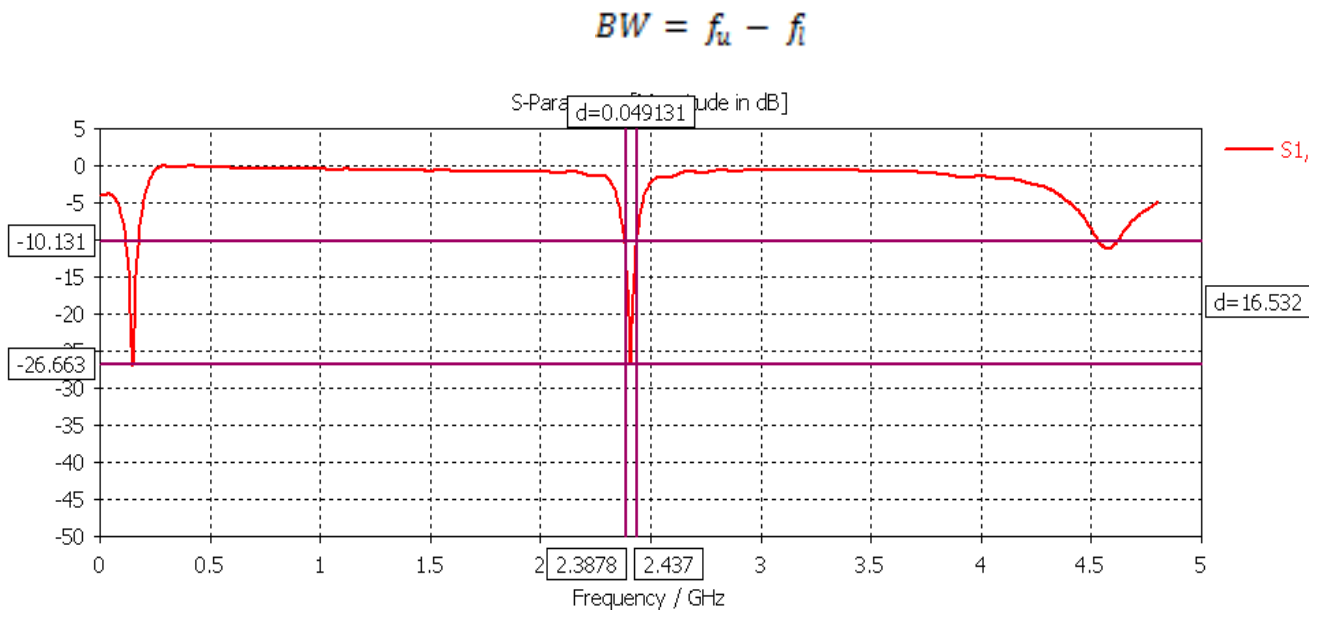

Gambar 7. Hasil simulasi bandwidth antena mikrostrip hexagonal single patch pada frekuensi $2,4 \mathrm{GHz}$ 


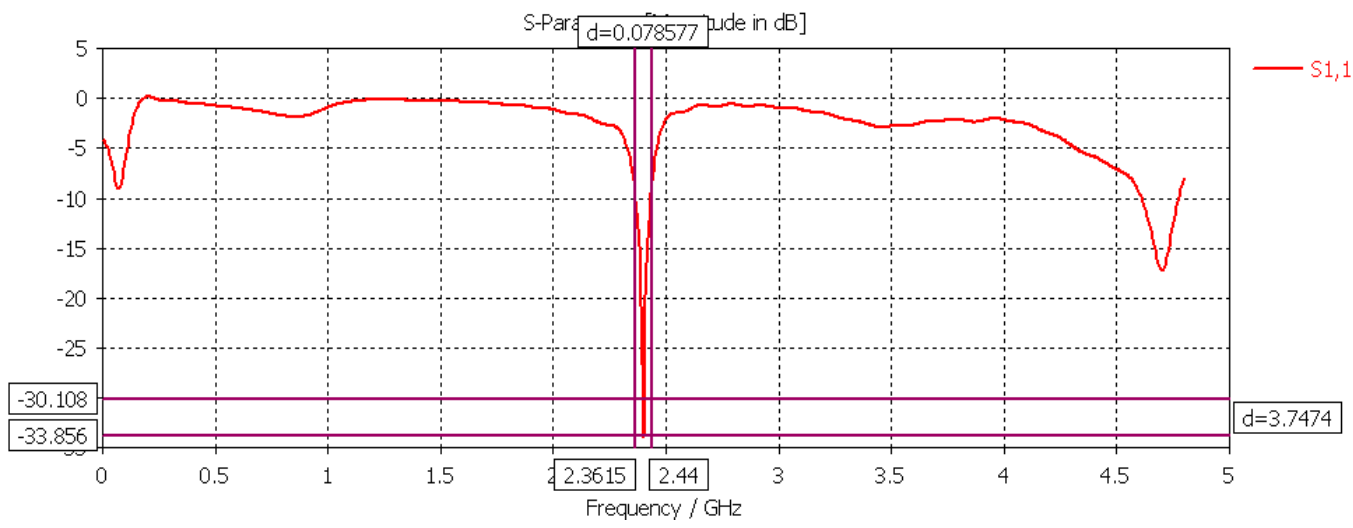

Gambar 8. Hasil simulasi bandwidth antena mikrostrip hexagonal patch array pada frekuensi $2,4 \mathrm{GHz}$

Selanjutnya hasil perhitungan nilai bandwidth kedua antena (hexagonal single patch dan hexagonal patch array ditunujukkan seperti pada Tabel 3

Tabel 3. Hasil simulasi antena hexagonal single patch dan hexagonal patch array

\begin{tabular}{|c|c|c|}
\hline Hasil Simulasi & $\begin{array}{c}\text { Frekuensi } \\
\text { Resonansi } \\
(\mathbf{G H z})\end{array}$ & $\begin{array}{c}\text { Bandwidth } \\
(\mathbf{G H z})\end{array}$ \\
\hline Antena Hexagonal Single Patch & $2,38-2,43$ & 0,05 \\
\hline Antena Hexagonal Patch Array & $2,36-2,44$ & 0,08 \\
\hline
\end{tabular}

Tabel 3 menunjukkan bahwa nilai bandwidth antena hexagonal patch array lebih besar atau mengalami peningkatan 37,5\% dibandingkan dengan antena hexagonal single patch. Bandwidth antena hexagonal patch array adalah $0,08 \mathrm{GHz}$ dan antena hexagonal single patch sebesar 0,05 GHz.

\subsubsection{Gain}

Gain dari hasil simulasi dapat diperoleh dari grafik polar yang dapat dilihat dari magnitude main lobe yang dihasilkan oleh pola radiasi kedua antena mikrostrip hexagonal single patch dan hexagonal patch array seperti pada Gambar 9 dan Gambar 10.

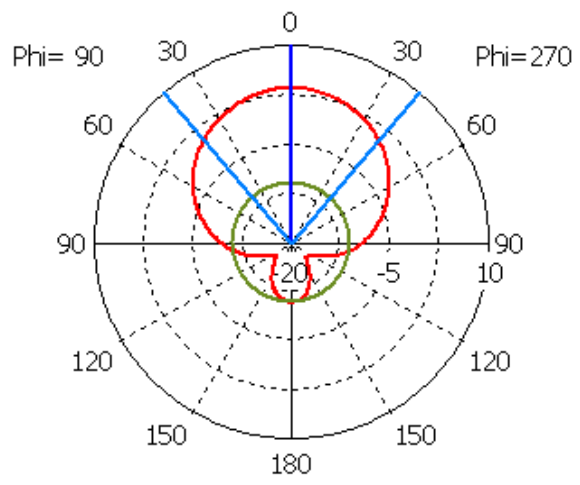

Gambar 9. Pola radiasi antena mikrostrip hexagonal single patch 


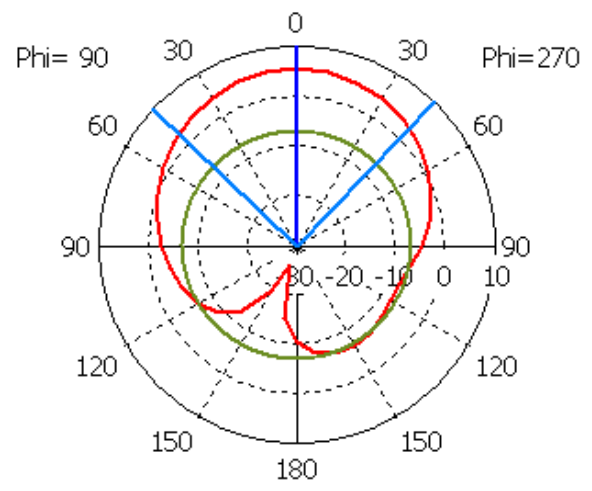

Gambar 10. Pola radiasi antena mikrostrip hexagonal patch array

Gambar 9 menunjukkan gain antena hexagonal single patch 3,51 dB, nilai Half Power Beam Width (HPBW) yang diperoleh adalah $80,3^{\circ}$. HPBW adalah lebar sudut yang memisahkan dua titik setengah daya pada pancaran utama dari pola radiasi. Titik penurunan setengah daya terletak pada $3 \mathrm{~dB}$. Nilai side lobe level (lobe kecil yang ada di dekat main lobe) pada pola radiasi antena adalah $-14,4 \mathrm{~dB}$. Sedangkan Gambar 10 menunjukkan gain antena hexagonal patch array yaitu $5,55 \mathrm{~dB}$, HPBW sebesar $90,5^{\circ}$ dan side load level $-12,4 \mathrm{~dB}$.

Berdasarkan Gambar 9 dan 10 dapat diketahui pula bahwa gain pada antena hexagonal yang disusun secara array mengalami peningkatan sebesar $36,75 \%$ dibandingkan antena hexagonal single patch.

\section{Kesimpulan}

Dalam penelitian ini, telah dilakukan desain antena hexagonal single patch dan hexagonal patch array. Metode yang digunakan untuk mendesain antena hexagonal patch array adalah metode Corporate Feed Line. Berdasarkan perbandingan parameter dari kedua antena tersebut dapat disimpulkan bahwa penambahan patch antena berpengaruh terhadap nilai gain dan bandwidth. Pada penelitian ini terjadi peningkatan nilai gain pada antena hexagonal patch array yaitu $5,55 \mathrm{~dB}$ atau $36,75 \%$ dibandingkan antena hexagonal single patch. Sedangkan peningkatan nilai bandwidth adalah 37,5\% dibandingkan antena hexagonal single patch. Selanjutnya untuk pengembangan penelitian ke depan adalah dapat digunakan metode desain lain misalnya series feed, FDTD dan juga bisa dilakukan penambahan patch antena

\section{Acknowledgment}

Penulis mengucapkan terima kasih kepada Bapak Isnandar selaku Direktur Politeknik Kota Malang yang telah memberikan arahan, masukan dan membimbing penulis dalam menyelesaikan penelitian mandiri ini. Penulis juga mengucapkan terima kasih kepada Bapak/Ibu Dosen TIM LP2M dan TIM Teknik Telekomunikasi yang telah memberikan dukungan dan saran yang membangun kepada penulis. 


\section{Daftar Pustaka}

[1] Constantine A.,Balanis, Antena Theory: Analysis Design, Third Edition. New Jersey: John Wiley \& Sons, Inc, 2005.

[2] Casu G, Moraru C and Kovacs A. Design and Implementation of Microstrip Antenna Array. IEEE. 2014.

[3] Kadam Suresh S, Mathpati Mahesh S. High Gain Compact Hexagonal Fractal Antenna. IOSR Journal of Electronics and Communications Engineering (IPSR-JECE). 2014; Vol. 9. Issue 6. PP 74-77

[4] Huque, Tanvir.,Al-Amin Chouwdury.,K Hosain and Shah Alam. Performance Analysis of Corporate Feed Rect angular Element and Circular Patch Elemen 4x2 Mikcrostrip Array Antenna. International Journal of Advanced Computer Science and Application (IJACSA). 2011; Vol.2. No.8

[5] Brancroft, R, Microstrip and Printed Antenna Design, 2nd Edition, USA: Scitech Publishing, Inc, 2009

[6] Pozar, David M, Microwave Engineerin, Fourth Edition, USA, 2011.

[7] Basu S, Srivastava A and Goswami A. Dual Frequency Hexagonal Microstrip Patch Antenna, International Journal of Scientific and Research Publications. 2013; Vol 3 Issues 7 